\title{
Development of augmented reality to learn history
}

\author{
Nur Hazirah Mohd Azhar, Norizan Mat Diah, Suzana Ahmad, Marina Ismail \\ Faculty of Computer and Mathematical Sciences, Universiti Teknologi MARA, 40450 Shah Alam, Selangor, Malaysia
}

\begin{tabular}{l} 
Article Info \\
\hline Article history: \\
Received Apr 30, 2019 \\
Revised May 30, 2019 \\
Accepted Jul 5, 2019 \\
\hline
\end{tabular}

\section{Keywords:}

Augmented reality

History

Learning

Melaka

\begin{abstract}
Augmented Reality (AR) is a technology that enables a new information delivery environment. AR promotes both engagement and motivation for people to obtain and acquire certain knowledge or information including those concerning history. People, especially the young generation, often view history as an uninteresting and boring subject matter. This may be due to the lack of interactivity and visual images that accompanying the information on history. This could affect our level of understanding about the history of our country such as the fall of Melaka Empire and weaken our spirit of patriotism. Thus, this research aims to study the effect of combining the AR technology together with the traditional information to create excitement in learning history. The development of the AR application in this project is to enhance the traditional book by allowing users to see the digital visual of historical events. The development of the application involves five phases that are analysis, design, develop, implement, and evaluate. The mobile application of AR book on the fall of Melaka Empire history has been developed successfully and the findings show that most users agree that the application contributes to higher users' satisfaction.
\end{abstract}

Copyright $@ 2019$ Institute of Advanced Engineering and Science. All rights reserved.

\section{Corresponding Author:}

Norizan Mat Diah,

Faculty of Computer and Mathematical Sciences,

Universiti Teknologi MARA,

40450 Shah Alam, Selangor, Malaysia.

Email: norizan@fskm.uitm.edu.my

\section{INTRODUCTION}

Historically, the Melaka Straits was one of the most important parts in the formation of the littoral states and strategic significance for world trade and regional development [1]. According to [2], the early stage of the history of Melaka started with the Malay Sultanate in the 15th century and followed by the period of the Portuguese and Dutch in the early of 16th century. Although UNESCO has listed Melaka as a World Heritage Site in 2008, there are certain issues that affect our society's knowledge about this important national history.

The society, especially the young generation, is not interested in getting to know the history that affects their understanding of the nation's past and the spirit of patriotism. History covers wide range of previous events on human beings, war stories and history of certain countries or politics [3]. In [4], the Johor's Chief Minister, Datuk Seri Mohamed Khaled Nordin said that some of the young generations nowadays do not appreciate the meaning of independence, and the spirit of patriotism is no longer instilled in their hearts. Nowadays, young people are becoming more materialistic and fascinated by the technology that they tend to forget the struggles of our leaders who had fought and sacrificed to gain independence for the country [4].

Refer to [4], people tend to neglect history because the subject is just full of text, thus, considered as uninteresting and boring. One of the causes of their ignorance and disinterest in history is due to the traditional information is not interactive and lack of visual information and pictures [5]. 
One of the solutions is to present the details of traditional information on history in an interactive way that includes visuals and images to attract people as offered by Augmented Reality (AR). AR is the latest technology that enables a new information delivery environment promoting both engagement and motivation for people to obtain and acquire knowledge. Thus, this research project aims to study the effect of combining AR technology with traditional information to entice people to learn history. The development of the AR application in this project is to enhance the traditional book by providing users with different digital views to view the historical events digitally.

\section{BACKGROUND OF STUDY}

Augmented reality (AR) is believed to be the next wave of online learning. New user experiences become possible to afford AR capabilities with the advent of powerful smartphones $[6,7]$. AR refers to the overlaying of digital content onto the physical objects or locations in the real environment [8]. It is also normally practiced by looking through the camera of devices such as a smartphone, tablet, webcam, or a head-mounted display. According to [9] AR can produce an amazing virtual result in which it fits live images or pictures that have been digitized into the user's real surrounding. AR has its resonance with a real environment in which information can be involved and people are able to learn through it [10].

Apple CEO, Tim Cook said that AR probably can give the world transformation and the future of it could be as immense as the smartphone [11]. In addition, Tim Cook also stated that AR has a resonance that not only involves in something, but it can also be part of people lives. Moreover, according to [9], Mark Zuckerberg stated that AR can be a large platform in the next 15 years and may replace desktops and smartphones.

Tim Cook also highlighted that many people do not like the idea of getting themselves out from the real environment for a long time [11]. Thus, AR is the best technology to be applied since it allows users to feel the real environment and at the same time connect them with the virtual things compared to Virtual Reality (VR) that put users out of the real environment [12]. Nowadays, AR has become one of the significant mediums to share information in an interactive way. It allows learners to view the digital information displayed in the physical world through Android or iOS devices. In addition, AR can enhance the learners' surrounding by allowing them to access inaccessible places and providing them with different views [10]. According to $[13,14]$ using AR for educational purposes can promote both engagement and motivation to the learners. [10] stated that AR could solve certain problems. He added that the learners could generate their own ideas developed through mobile devices and the environment, assisted by the AR technology.

The next examples are about how AR being applied in people's everyday life. Firstly, Microsoft creates an AR headset called Hololens to transform the way people work and interact with the world by overlays digital images in the real world [15]. A worker such as a car engineer and architect no longer depend on the keyboard and mouse while working since the Hololens enables the users to use hand gestures in the air by swiping, zooming, and selecting the digital information that will be displayed onto their surroundings.

Next, AR can be used in a sport like the Solo's Augmented Reality cycling glasses that are designed to monitor the wearer's heart rate, calories burned and navigation while they are cycling. This device is already being used by the U.S. Olympics cycling team. Another device for skiing that is RideOn's Ski Goggles uses AR to provide real-time data such as the weather temperature, heart rate, time and many others while the user is on the slopes. Furthermore, Google Translate application uses AR to breakdown language barriers. By utilizing the camera's viewfinder and holding it in front of any text on menus, road signs, or directions, the application will quickly translate the text into 29 languages [15].

Greene [8] predicted that in the next few years, AR can make into a billion of dollars in the industry and it is a powerful new medium that people will not ignore. Greene also added that many scholars starting to explore the use of AR as a practical medium of learning engagement within the information given. To conclude, AR technology is the next immense technology that can be used whether at work or at home.

\subsection{The importance of augmented reality in history of melaka}

Melaka is known as a popular tourism place among local and international visitors and contains lots of heritage sites and historical past. In 2004, Melaka attracted 4 million international and local visitors and they mostly visited the historical city [16]. Even though Melaka attracted many local visitors, there are still certain issues that affect our society's knowledge and understanding about the history of our country such as the fall of Melaka Empire. [17], one of the issues is that all the traditional information displays are not interactive and interesting for visitors due to the lack of visual information and pictures about the history. They also said that brief description and few pictures are not enough to reveal the history of the sites and visitors need more than that because they want to learn something during their visit. 
Another issue is many people dislike and easily disremembers our history. [18] stated that the number of young people who do not know about the earlier history of our country is progressively growing. These phenomena could affect our society's understanding of our country's history such as the fall of Melaka Empire and weaken our spirit of patriotism. The spirit of patriotism arises when we know and understand who we are as a nation country because of having a solid knowledge of our country's history. However, many of the young generation today only learn history solely to pass the examinations either at the school level or at the university. Unfortunately, they fail to understand the importance of history subject and as the result; they become citizens who are blind to their own country's history.

One of the ways to create awareness among people, especially the young generation, is that they can learn through the history book that incorporates AR that supports 3D models, sound, and animation. Even though the AR application consists of multimedia elements, it is still considered new and foreign among the public in Malaysia. Through observation, there is no AR application concerning the fall of Melaka Empire history in which, in this context, the traditional information (book) is still being used but enhanced by digital technology.

\section{METHODOLOGY}

The methodology system model being used in this project involves five phases, namely analysis, design, develop, implement, and evaluate. The five phases ensure the project is developed with specific learning goals and provide the users with the right information of the study.

\subsection{Analysis}

The analysis phase is one of the important processes to gather information and plan for project development. The first activity starts with defining the project title that is The Fall of Melaka Empire History using Augmented Reality Mobile Application. It is followed by data gathering to get insights about this project. Research is conducted to get relevant information about Melaka, its history, AR, and other related information concerning the project. Among the sources of data are from articles, journals, proceedings, books, and trusted websites. Once the data is analysed, the objectives, problems, scope, limitations, and significance of the project are determined.

\subsection{Design}

In this phase, the first activity is to get all the information from the gathered data in the analysis phase. Next, the content of the AR book concerning the fall of Melaka Empire history is being selected and arranged accordingly. After the arrangement of the content, the multimedia elements such as animations, images, and sounds are developed and selected to be incorporated as part of the content of the AR book.

A completed flowchart and storyboard for this project are also developed in this phase. The flowchart illustrates the process of how the application works or should work using simple words or layman terms that easily understood. In addition, the storyboard illustrates the actual flow when the users use the application.

a. Flowchart: Refer to Figure 1, that shows the flowchart of the project. It starts with the main menu that displays options such as camera, instruction, and quiz buttons. If the users want to know how to use the application, they can click the instruction button in which the instruction page will be displayed. In order to go to the smartphone's camera, the users need to go back to the homepage and upon choosing the image target in the book; they can click the camera button and point the camera to the image target. Once the camera detected the marker on the image, it will display the AR content. The users can go back to the main menu or continue to view other AR content on different image targets. In order for the users to test their knowledge based on what they have read in the book, they can answer the questions in the quiz section. Once the users finished answering the questions, the score will be displayed based on the number of correct answers.

b. Storyboard: Storyboard is a graphic representation displayed in sequence on how the project works and its content. Figure 1, shows the storyboard of the project developed during the brainstorming session. 

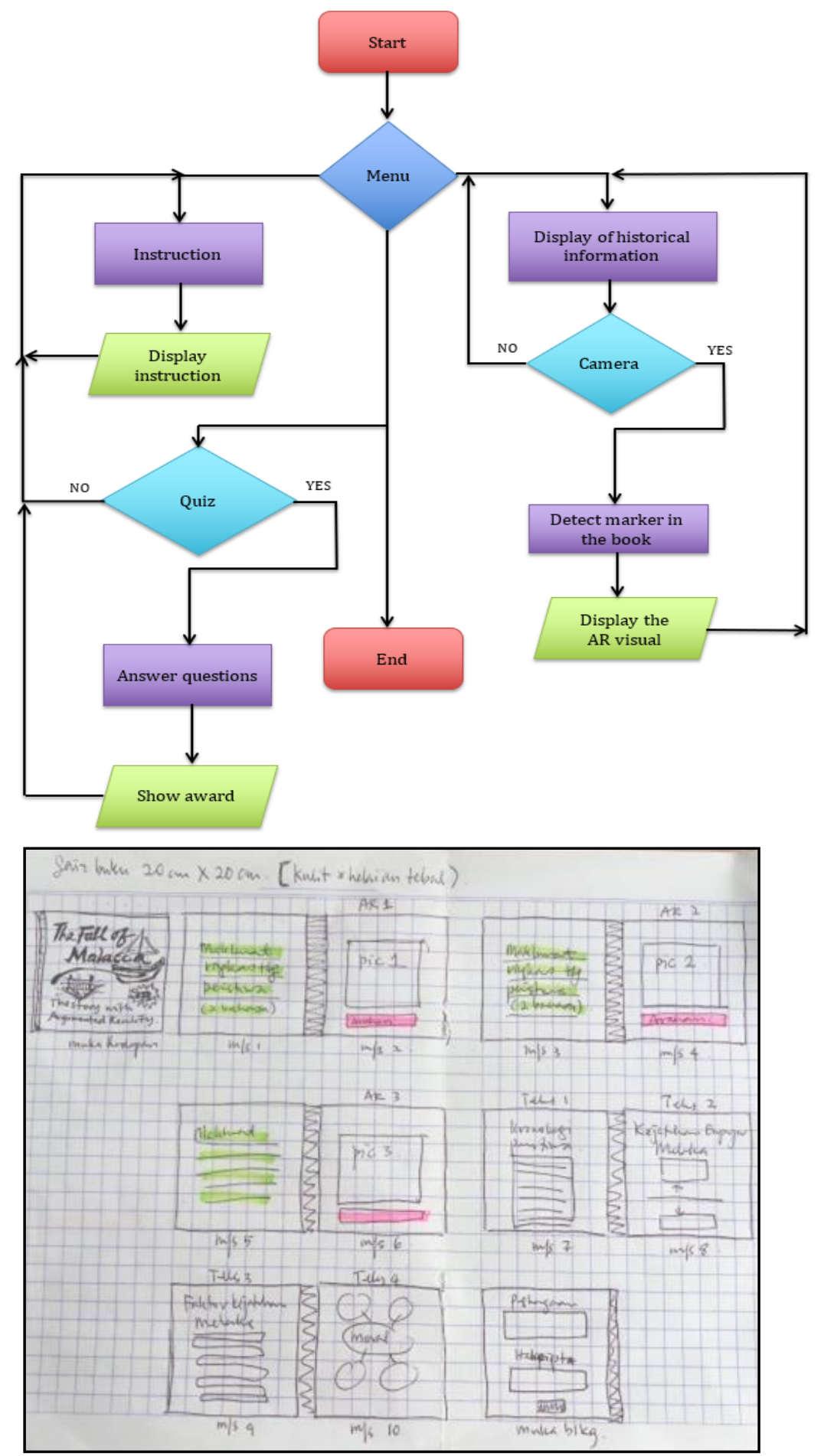

Figure 1. Flowchart of the project and story board

\subsection{Development}

Figure 2, illustrates the development process for creating the objects or markers for the content in the AR book and mobile application that will be used as a medium to display the digital content. The first step is to create the 3D models in 3ds Max. Then, the 3D models will be imported into Unity. The image targets are loaded into Vuforia and imported as a package into Unity. The 3D models are then attached to the image targets. Next, the printable book that includes the image targets that serve as markers for the 
augmented digital content is designed. Finally, the mobile application is built to view the augmented digital content through mobile cameras.

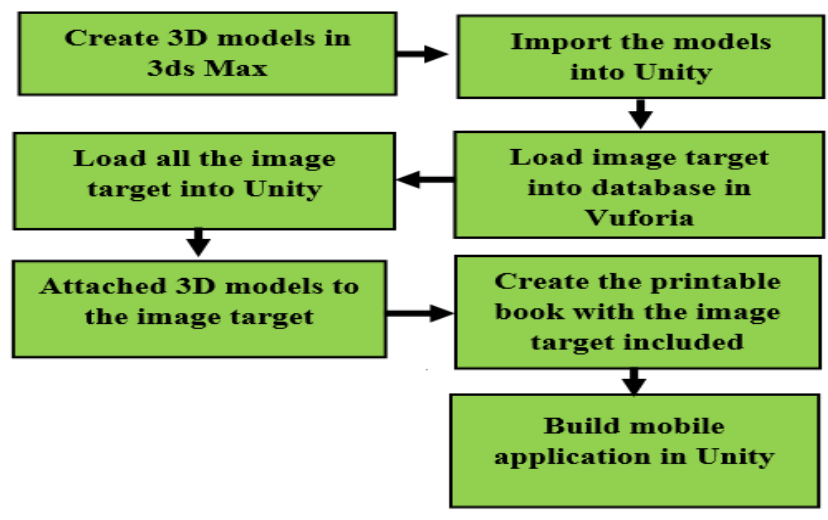

Figure 2. Development process

\subsection{Implement}

In this phase, the prototype developed in the development phase is introduced to the target audience. The target audience who consists of the public is briefed on how to use the mobile application. The mobile application is installed in smartphones and the printed AR books are ready to be distributed. The prototype is introduced and demonstrated at places with crowds such as university and recreation park in which people with different age and background can test the prototype.

\subsection{Evaluate}

For the purpose of evaluation, this project using usability tests using USE questionnaire based on $[19,20]$. Usability is one of the most important quality characteristics of a product or system. Usable systems are often easy to learn, efficient, not error-prone and satisfactory in use [21, 22]. Twenty (20) people aged between 13 and 25 years old are required to evaluate the system. This age group is in the formal operational stage based on Piaget's Theory. In this stage, the people have the abilities to think about hypothetical scenarios, logically test hypothesis, and process abstract thoughts [23]. The evaluation aims to find out the satisfaction level of using the AR book with a mobile application.

The USE questionnaire is divided into four sections that are usefulness, satisfaction, ease of use, and ease of learning. The level of agreement is from 1 to 7 that is based on [24, 25] in likers-type scale response anchors in which 1 indicates strongly disagree, 2 for disagree, 3 for somewhat disagree, 4 for neither agree nor disagree, 5 for somewhat agree, 6 for agree, and 7 for strongly agree.

\section{RESULT AND FINDING}

The analysis in the evaluation phase is done based on the answered questionnaire. Overall, most of the feedback obtained based on the 12 questions are positive and encouraging. The analysis of the questionnaire is divided into four sections: Usefulness (Question 1 and 2), Ease of Use ( Question 3,4,5, and 6), Ease of Learning (Question 7 and 8) and Satisfaction (Question 9, 10, 11and 12).

\subsection{Usefulness}

Referring to Figure 3, for Question 1, the finding shows that 59\% and 29\% of the users strongly agree and agree that the AR application is useful, respectively. Only 6\% of the users neither agree nor disagree and the remaining $6 \%$ of the users somewhat disagree that the AR mobile application is useful.

In addition, the finding shows that, for Question 2, 53\% of the users strongly agree and $29 \%$ of the users agree that the AR mobile application with mobile application meets their needs. Meanwhile, only $6 \%$ of the users somewhat agree and the remaining $12 \%$ of the users neither agree nor disagree that the AR mobile application meets their needs. 


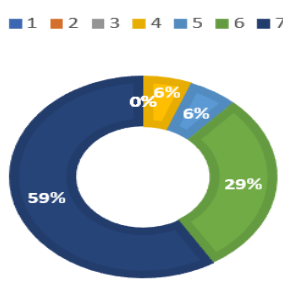

It is useful (Q1)

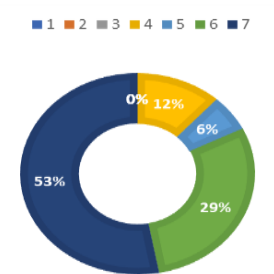

It meets my needs $(\mathrm{Q} 2)$

Figure 3. Findings for Question 1 and Question 2

\subsection{Ease of use}

The finding for Question 3, finds that $70 \%$ and $18 \%$ of the users strongly agree and agree that the AR mobile application is easy to use, respectively. On the other hand, $6 \%$ of the users neither agree nor disagree while the remaining 6\% somewhat disagree that the AR mobile application is easy to use.

Based on the finding for Question 4, 70\% of the users strongly agree and followed by $18 \%$ of the users agree that the AR mobile application is simple to use. However, $12 \%$ of the users neither agree nor disagree that the AR mobile application is simple to use.

The finding of analysis for Question 5 in which $59 \%$ of the users strongly agree that the AR mobile application is user-friendly. Meanwhile, $29 \%$ and $12 \%$ of the users agree and somewhat agree that the AR mobile application is user-friendly, respectively.

The analysis for Question $6.41 \%$ of the users strongly agree and $41 \%$ of users agree that it is effortless to use the AR mobile application, respectively. Meanwhile, 18\% of the users somewhat agree that it is effortless to use the AR mobile application.

\subsection{Ease of learning}

Referring to Figure 4, the finding for Question 7 shows that $53 \%$ and $41 \%$ of the users strongly agree and agree that they easily remember how to use the AR mobile application, respectively. However, $6 \%$ of the users neither agree nor disagree that they easily remember how to use the AR mobile application.

Moreover, based on the finding for Question 8 (Figure 4), 65\% of the users strongly agree that it is easy to learn to use the AR mobile application. This is followed by $35 \%$ of the users who agree that it is easy to learn to use the AR mobile application.

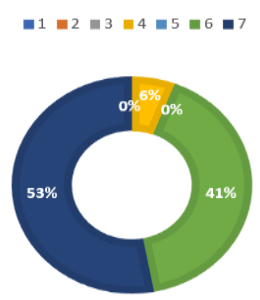

I easily remember how to use it (Q7)

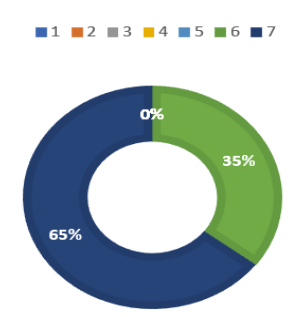

It is easy to learn to use it (Q8)

Figure 4. Findings for Question 7 and Question 8

\subsection{Satisfaction}

The finding for Question 9, as shown in Figure 5, finds that $82 \%$ and $12 \%$ of the users strongly agree and agree that they are satisfied with the AR mobile application, respectively. In addition, $6 \%$ of the users somewhat agree that they are satisfied with the AR mobile application.

Based on the finding for Question 10 (Figure 5), 76\% and 18\% of the users strongly agree and agree that they would recommend the AR mobile application to their friends. In addition, $6 \%$ of the users somewhat agree that they would recommend the AR mobile application to their friends.

Finding of analysis for Question 11 in which $82 \%$ of users strongly agree that it is fun to use the AR mobile application. Meanwhile, $18 \%$ of the users agree that it is fun to use the AR mobile application. The 
finding of analysis for Question $12.71 \%$ and $23 \%$ of the users strongly agree and agree that they feel that they need to have the AR mobile application, respectively. Meanwhile, $6 \%$ of the users neither agree nor disagree that they feel that they need to have the AR mobile application.

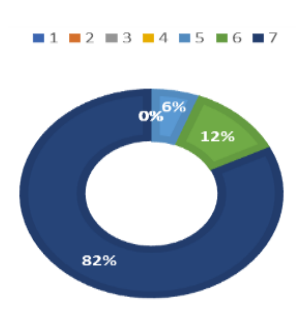

I am satisfied with it (Q9)

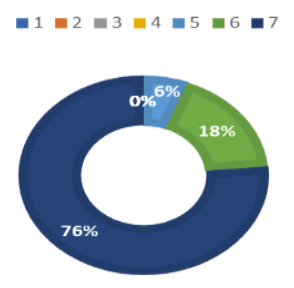

I would recommend it to friends (Q10)

Figure 5. Findings for Question 9 and Question 10

\section{CONCLUSION}

This application exposes the users to the fall of Melaka Empire history that may be forgotten in this generation. The first objective is achieved by identifying the multimedia elements for the AR book such as text, audio, animation, and interactive content like AR content. The book that is enhanced by AR through a mobile application, which makes it different from a traditional book, is proven able to attract people's attention to read the book. With the emergence of many new technologies nowadays, this project hopes to expose the users to one of the technologies that is Augmented Reality. The users can view the 3D models in the real world by using the camera in the mobile application that points to the marker or image target. In addition, the users can also test their knowledge based on what they have read in the book by answering the quiz questions. Based on the findings, the majority of the users are satisfied with the AR book with a mobile application. Nevertheless, the book can still function as an ordinary book to continue spreading the knowledge, thus, the aim to provide the awareness about the history to people, especially the young generation, will not stop even without the mobile application.

\section{ACKNOWLEDGEMENTS}

The authors would like to thank Faculty of Computer and Mathematical Sciences, Universiti Teknologi MARA, Shah Alam, Selangor, for sponsoring this research.

\section{REFERENCES}

[1] E. Hans-Dieter, S. Gerke, "The Strategic Importance of the Straits of Malacca for World Trade and Regional Development," ZEF Working Paper Series No. 17, 2006.

[2] United Nations Educational, Scientific and Cultural Organization. Melaka and George Town, Historic Cities of the Straits of Malacca, Retrieved April 6, 2017, from http://whc.unesco.org/en/list/1223. 2011.

[3] I. Ismail, M. Ismail, F. H. A. Razak. "Framework for Mobile Historical Event Storytelling." 13th International Conference on Applied Computer and Applied Computational Science (ACACOS '14), 2014.

[4] Johor MB concerned with lack of patriotism among the young generation. (2014, August 18). astro AWANI. Retrieved April 16, 2017, from http://english.astroawani.com/merdeka2014/johor-mb-concerned-lack-patriotismamong-young-generation-42103.2017.

[5] Z. Syamsul Bahrin, P. Ulka Chandini and A. B. Juliana Aida "Applicability of mobile augmented reality usage at Melaka cultural heritage sites." In: 5th International Conference on Computing and Informatics (ICOCI), Aug 2015, pp 11-13. 2015.

[6] A. A. Khairuddin, F. Redzuan, N.A. Daud, "Evaluating Students' Emotional Response in Augmented Reality-Based Mobile Learning Using Kansei Engineering." International Conference on User Science and Engineering, pp79-89. 2018.

[7] N. M. Noor, F.H.Yusoff, R. L.Yussof, M. Ismail, "The Potential Use Of Augmented Reality In Gamification". Proceedings of the 5th International Conference on Computing and Informatics, ICOCI 2015, pp 159-167. 2015.

[8] J. W. Greene (July 24). Introduction to mobile augmented reality development in unity. Retrieved May 20, 2017 from http://programminghistorian.org/lessons/intro-to-augmented-reality-with-unity. 2016.

[9] Y. Levski, (2018, Dec 28). Augmented Reality Takes the Pilot Seat on AR Drones. Retrieved March 22, from AppReal: https://appreal-vr.com/blog/augmented-reality-and-drones/ 2018.

[10] E. FitzGerald, R. Ferguson, A. Adams, M. Gaved, Y. "Mor, R. Thomas. Augmented reality and mobile learning: the state of the art". International Journal of Mobile and Blended Learning, vol. 5, no. 4, pp 43-58. 2013. 
[11] R. Wong, (2017, February 11). Apple CEO Tim Cook says AR could be as big as the smartphone. Retrieved April 24, from http://mashable.com/2017/02/10/tim-cook-augmented-reality-opportunity-apple/\#3exV13Bo3aqy.2017.

[12] B. Dalgarno, M.J. W. Lee, "What are the learning affordances of 3-Dvirtual environments?" British Journal of Educational Technology, vol. 4, no. 1, pp.10-32. 2010.

[13] E. Klopfer, J. Perry, K. Squire, M. F. Jan, "Collaborative learning through augmented reality role playing," Proceedings of conference on Computer support for collaborative learning, International Society of the Learning Sciences, May 2005, pp 311-315. 2005.

[14] H. M. Huang, S.H. Liaw, "A case study of learners' motivation and intention to use augmented reality learning system", WIT Transactions on Information and Communication Technologies. 49, pp 995-1002. 2014.

[15] G. Barrat (2016, December 20). Forget Pokémon GO-these are the augmented reality experiences that'll soon be invading your life. Retrieved May 21, from http://www.mirror.co.uk/tech/forget-pokmon-go-augmented-reality8659104. 2017.

[16] N. A. Mohamed. Mobile apps: Malacca historical places. Retrieved from http://eprints.utem.edu.my/14938/1/MOBILE\%20APPS\%20MALACCA\%20HISTORICAL\%20PLACES.pdf. 2014.

[17] U. C. Pendit, S. Zaibon, "Non-personal digital interpretive media at cultural heritage sites," In: Proceedings of the 4th International Conference on Computing and Informatics (ICOCI 2013), pp. 346-351. Sarawak, Malaysia. 2013.

[18] F. Fernando (2015, Aug 21). The history of the emergency era is increasingly forgotten (in Indonesia: Sejarah zaman darurat semakin dilupakan), Retrieved May 20, http://bm.therakyatpost.com/berita/2015/08/21/sejarahzaman-darurat-semakin-dilupakan. 2018.

[19] A. Lund, "Measuring usability with the USE questionnaire," Usability and User Experience Newsletter, STC Usability SIG, vol.8, no.2, pp.1-4 2001.

[20] L. A. Freeman, L. M. Jessup, "The power and benefits of concept mapping: measuring use, usefulness, ease of use, and satisfaction", International Journal of Science Education, vol. 2, no. 2, pp.151-169. 2004.

[21] N. M. Diah, M. Ismail, S. Ahmad, Mohd K. M. Dahari, "Usability testing for educational computer game using observation method," International Conference on Information Retrieval \& Knowledge Management, (CAMP), pp.157-161. 2010.

[22] M. Ismail, N.M. Diah, S. Ahmad, N. A. M. Kamal and M. K. M. Dahari "Measuring Usability of Educational Computer Games Based on The User Success Rate." International Symposium on Humanities, Science \& Engineering Research (SHUSER), pp. 56-60. 2011.

[23] McLeod, S., Jean Piaget's Theory of Cognitive Development, Retrieved December 3, 2017, from https://www.simplypsychology.org/piaget.html. 2017.

[24] M. V. Wade. Liken-type scale response anchors. Clemson International Institute for Tourism \& Research Development, Development of parks, Recreation and Tourism Management. Clemson University. 2006.

[25] M. Gao, P. Kortum, F. Oswald, "Psychometric Evaluation of the USE (Usefulness, Satisfaction, and Ease of use) Questionnaire for Reliability and Validity," Proceedings of the Human Factors and Ergonomics Society Annual Meeting, vol. 62, no.1, pp.1414-1418. 2018. 